\title{
DELIO EN EL ARGÉNTEO MONTE: NUEVOS DATOS EN TORNO A LA VIDA DE DIEGO MEXÍA DE FERNANGIL EN LA VILLA IMPERIAL DE POTOSÍ ${ }^{1}$
}

Delio on Mount Argenteo: new data relating to the life of Diego Mexía de Fernangil in the Imperial Village of Potosi

Pablo Luis Quisbert Condori*

Resumen

A partir de documentación inédita, este trabajo ofrece nuevos datos sobre la vida del poeta Diego Mexía de Fernangil en la Villa Imperial de Potosí; sus actividades mercantiles, sus relaciones personales, su situación familiar y hasta detalles sobre su muerte, acaecida en 1634 .

Palabras clave: Diego Mexía de Fernangil, literatura colonial, Potosí, Charcas, siglo XVII. Abstract

Based on new archival information, this article examines as-of-yet unknown details of the life of poet Diego Mexía de Fernangil in Potosí; his mercantile activities, personal relationships, family life, as well as details of his death in 1634 .

Key words: Diego Mexía de Fernangil, colonial literature, Potosí, Charcas, XVII century.

Desde que José de la Riva Agüero presentara, en 1914, una renovada mirada biográfica sobre el poeta sevillano Diego Mexía de Fernangil, autor de La Primera Parte del Parnaso Antártico de obras amatorias, se han hecho sucesivas contribuciones que muestran la vida activa y creativa de este poeta sevillano en las Indias. Sin embargo, casi todos los trabajos abordan la vida de Mexía de Fernangil hasta la década de 1610, cuando abandona Lima para radicar definitivamente en la Villa Imperial de Potosí. ${ }^{2}$

Así pues, bien poco se conoce sobre los más de veinte años que Diego Mexía de Fernangil vivió en Potosí. En este trabajo, de alcance biográfico más que literario, se intenta llenar ese vacío, mostrando algunos episodios de la vida del poeta en la ciudad minera, aclarando asimismo algunos aspectos de su biografía y logrando establecer las circunstancias y la fecha de su muerte; para ello se ha utilizado una serie de fuentes inéditas, provenientes en su mayor parte del Archivo Histórico de la Casa de la Moneda de Potosí, entre las que

\footnotetext{
${ }^{1}$ Este trabajo debe mucho a la generosa colaboración de Andrés Eichmann, Mariela Insúa y Marcela Inch. A ellos va dirigido mi agradecimiento.

${ }^{2}$ Entre estos trabajos se puede mencionar a Pociña (1983), Lohmann Villena (1999), Barrera López (1985-2009). Hasta ahora, la semblanza biográfica más completa del poeta sevillano la proporciona Gil Fernández (2008).
} 


\section{Pablo Luis Quisbert Condori}

destacan: el poder para testar que otorgó, el testamento que se hizo en virtud a dicho poder y el inventario de sus bienes. ${ }^{3}$

MERCADER ITINERANTE

Los primeros registros notariales que se han encontrado, por ahora, de sus actividades en la Villa Imperial de Potosí, datan del año 1604. El poeta radicaba por entonces en Lima y realizaba frecuentes viajes a la urbe minera llevando mercaderías. Al parecer 1604 fue un año excelente para los negocios de Diego Mexía en Potosí, quien pudo haber pasado la mayor parte del año en la Villa y como resultado de sus operaciones mercantiles hizo diversos envíos de plata, tanto en monedas como en barras, desde esa ciudad hasta Lima. ${ }^{4}$

Las escrituras notariales de estas remisiones muestran que los diversos dueños de recuas que contrató Mexía de Fernangil, debían transportar la plata hasta el puerto de San Marcos de Arica donde el poeta tenía una persona de su confianza, un vecino de Arica llamado Diego Salguero de Saavedra, a quien se debían entregar las barras y monedas de plata. Sólo en caso de ausencia de Salguero, la plata debía ser entregada a Francisco Vásquez, vecino y alguacil mayor de Arica o a Juan Gonzáles Morago, escribano público de Arica. Estas tres personas formaban parte de la red mercantil y de amistades de la cual se valía el poeta para realizar sus negocios.

Estos corresponsales en Arica debían, luego, registrar las barras y monedas en un navío con rumbo al Callao, cuyo destino final era la ciudad de Lima. Las cuatro primeras partidas están consignadas a nombre de doña María de Miranda, su mujer, quien - por lo visto - se hacía cargo de llevar los negocios en la capital del virreinato. Del conjunto de envíos, la segunda partida estaba dirigida a María de Miranda en exclusividad y en la primera, la tercera y la cuarta compartía responsabilidad con dos mercaderes limeños, Tomás de Arauz y Sebastián González Salgado quienes eran sus

\footnotetext{
${ }^{3}$ Estos documentos serán publicados en su integridad en el Anuario del Archivo y Biblioteca Nacionales de Bolivia, en el número correspondiente al 2011. En lo que sigue, recurriremos a las siguientes abreviaturas: Archivo Histórico de Potosí - Casa de la Moneda Potosí (AHP), Archivo y Bibliotecas Nacionales de Bolivia - Sucre (ABNB), Archivo de La Paz - La Paz (ALP), Archivo General de Indias - Sevilla (AGI), Biblioteca Nacional de España - Madrid (BNE).

${ }^{4}$ Los envíos de plata desde Potosí a Lima, hechos por Diego Mexía de Fernangil en 1604 fueron los siguientes: 1) AHP/EN 38 fs. 964r-964v, Potosí 23-III-1604, 3.728 pesos, 5 tomines, 5 granos en plata ensayada, con destino a María de Miranda o Tomás de Arauz. 2) AHP/EN 38 fs. 940v-941r, Potosí 13-IV-1604, 500 pesos para María de Miranda. 3) AHP/EN 38 fs. 1148v-1150v, Potosí 26IV-1604, 4.406 pesos, 7 tomines, 6 granos en plata ensayada, destinatarios María de Miranda, Tomás de Arauz y Sebastián González Salgado. 4) AHP/EN 37 fs. 2131r-2131v, Potosí 20-VII1604, 6.710 pesos, 1 tomín, 8 granos, en plata ensayada (equivalía a 10.720 pesos y 5 tomines en pesos corrientes), dirigidos a María de Miranda o Tomás de Arauz. 5) AHP/EN 37 fs. 2747r-2747v, Potosí 18-IX-1604, 534 pesos, 1 tomín, 5 granos de plata ensayada (deducidos los gastos, equivalía a 853 pesos, 5 tomines en pesos corrientes), destinatario Juan de Terrazas.
} 


\section{Delio en el argénteo monte: Nuevos datos en torno a la vida de Diego Mexía}

socios comerciales. El quinto envío estaba dirigido exclusivamente al mercader Juan de Terrazas, a quien Diego Mexía enviaba 534 pesos de plata ensayada; diciéndole "...de resto de lo procedido de la ropa que ha vendido de su cuenta en esta dicha villa" (AHP/EN 37 f., 2747r).

La suma total que envió a Lima era bastante considerable, y una gran parte parece corresponder a sus propios negocios. ${ }^{5}$ Esto quiere decir que, a inicios del siglo XVII, la situación económica del poeta era bastante auspiciosa, lo que le habría permitido planificar un viaje a España en 1606 para realizar, entre otras cosas, las tratativas para la impresión de la primera parte de su Parnaso Antártico. Sin embargo, por lo que menciona Juan Gil Fernández, no hay constancia de que el poeta hubiera realizado este ansiado viaje (2008:76).

Mexía de Fernangil está de regreso en Potosí a inicios de $1607 .{ }^{6}$ De ahí en adelante habría que pensar que volvió a viajar al norte, puesto que Juan Gil lo ubica en Lima en 1609, donde habría padecido junto a su familia el terrible terremoto que asoló la capital del virreinato el 9 de octubre de 1609. Como efecto del temblor, su hija Magdalena habría adquirido el "mal de corazón", el cual se curaría sólo con el uso de una reliquia de Francisco Solano. ${ }^{7}$

\section{VECINO DE LA VILLA IMPERIAL DE POTOSí}

En algún momento de la década de 1610, Mexía de Fernangil decide establecerse en la Villa Imperial de Potosí. Los motivos los explica en la dedicatoria que el 15 de enero de 1617 hizo al virrey Príncipe de Esquilache, de la Segunda parte del Parnaso Antártico de divinos poemas

Pues habiendo por espacio destos ocho años últimos corrido por mis negocios tan deshecha tormenta, que habiéndome llevado los más de los bienes que llaman de fortuna, me recogí en esta Imperial Villa con mi familia, como en seguro puerto, esperando pasase el rigor deste airado

\footnotetext{
${ }^{5}$ Diego Mexía de Fernangil hizo otro envío de 600 pesos de plata corriente a Arica, la escritura es de 22 de septiembre de 1604. Sin embargo, no dejó establecido si la plata debía ser enviada a Lima o no (AHP/EN 37 fs. 2849v-2850). Asimismo, en el envío de 26 de abril de 1604, junto a los 4.406 pesos de plata ensayada, Diego Mexía envió también 165 pesos corrientes, los cuales provenían de deudas que había cobrado en Potosí para sus corresponsales en Arica (AHP/EN 38 fs. 1148v-1150v).

${ }^{6}$ AHP/EN 40 fs. 72r-72v. Obligación, Juan de Torres a Diego Mexía de Fernangil, Potosí 10 de enero de 1607. Juan de Torres declara deber a Mexía de Fernangil, 2.247 pesos de plata corriente, por 374 varas de paño de Quito que el poeta-mercader le había entregado. La escritura aclara, asimismo, que la mitad de la suma correspondía a Sebastián González Salgado, uno de los socios comerciales de Diego Mexía de Fernangil. Este mismo documento lo sitúa en la Villa Imperial en septiembre del mismo año. Sobre Sebastián González Salgado ver Gil Fernández (2008:77).

${ }^{7}$ El episodio es relatado por Diego de Córdova (1676:347-348). La muerte de Francisco Solano se produjo el 14 de julio de 1610, por lo que la curación milagrosa de la hija de Diego Mexía de Fernangil debería haberse producido con posterioridad a esta fecha. Este episodio fue dado a conocer por Lohmann Villena (1999:126).
} 


\section{Pablo Luis Quisbert Condori}

invierno, donde con quietud he gozado de los bienes del entendimiento, sobre quien no tiene la fortuna dominio ni imperio alguno. ${ }^{8}$

Potosí, la ciudad del "argénteo monte" como Mexía de Fernangil denominó al Cerro Rico, con su intenso trasiego comercial, era el lugar ideal para que recomenzara sus actividades mercantiles. Así, el poeta reaparece en las escrituras notariales potosinas en 1612, pues el 15 de junio de ese año hizo una escritura de obligación a favor de Gaspar Rivamartín. ${ }^{9}$ La estancia del poeta en Potosí, que debía ser temporal, con el tiempo se fue convirtiendo en permanente y definitiva; y así en 1615, declara ser ya "mercader vecino desta dicha villa". ${ }^{10}$

Ya avecindado, Mexía de Fernangil realiza una serie de negocios con una red de familias y de personas dedicadas al comercio. De hecho, una de ellas, la de los Mayuelo, ${ }^{11}$ estrecharía vínculos con la de Mexía de Fernangil al casarse Diego, uno de sus miembros, con Catalina, una de las hijas del poeta.

Otra de las personas con quien el poeta-mercader se relacionó, fue Pedro Julián Mondragón; lazos que se estrecharían aún más con la boda, en fecha aún no conocida, de Pedro Julián con Francisca de Miranda, hija del poeta. Pedro Julián Mondragón parece haberse iniciado como comerciante y luego haber dado el salto a las actividades mineras, llegando a poseer minas y un ingenio para el beneficio de los metales del Cerro Rico. ${ }^{12}$ Es en este contexto personal

${ }^{8}$ Diego Mexía de Fernangil, La segunda parte del Parnaso Antártico de divinos poemas. Manuscrito de la Bibliothèque Nationale de France BNF/ESP 389 f. 177r. Deseo hacer llegar un agradecimiento especial a Andrés Eichmann por haberme facilitado una copia de este documento y, por su intermedio, a Tatiana Alvarado, quien prepara una edición crítica de la obra de Mexía de Fernangil.

9 AHP/EN 44 fs. 940r-940v. Obligación, Diego Mexía de Fernangil a Gaspar de Rivamartín, Potosí 15 de junio de 1612. Mexía de Fernangil se había prestado 3.000 pesos de plata corriente de Rivamartín; los cuales pagó a inicios de septiembre del mismo año.

${ }^{10}$ En mayo de 1615 , Mexía de Fernangil arrendó por dos años una tienda con su trastienda en la plaza principal de Potosí, por 600 pesos corrientes, cifra que pagó al contado. (AHP/EN 48 fs. 1175v-1176r). Arrendamiento de tienda, Alonso Caro a Diego Mexía de Fernangil. Potosí 11 de mayo de 1615. Caro dijo que la tienda se encontraba “...encima de mis casas principales en la plaza pública de esta villa". Por cierto que Alonso Caro dijo, a su vez, haber arrendado la tienda del mayordomo de la cofradía de la Veracruz. La tienda parece haber sido, pues, propiedad de la Cofradía de la Santa Veracruz, de la cual, como se verá, era miembro el mismo Mexía de Fernangil.

${ }^{11}$ En 1615, la situación económica de Mexía de Fernangil parece mostrar cierta mejoría, puesto que en 8 de marzo de ese año prestó a Diego Mayuelo "el viejo", a Lázaro Mayuelo y a Pedro Julián Mondragón, quien llegaría a ser también yerno del poeta, 6.354 pesos corrientes en seis barras de plata (AHP/EN 48 fs. 768r-770v). Deudo. Diego de Mayuelo, Lázaro Mayuelo y Pedro Julián Mondragón, a Diego Mexía de Fernangil. Potosí, 8 de marzo de 1615.

${ }^{12}$ Incluso es probable que ya poseyera su ingenio en 1619, cuando en noviembre de ese año Diego Mexía lo apoyó, siendo su fiador, en un negocio de compra de azogue de manos del veinticuatro Martín de Zamudio. (AHP/EN 52 fs. 2439v-2441r.). Obligación: Pedro Julián Mondragón, deudor, y Diego Mexía de Fernangil su fiador, a Martín de Zamudio, albacea y testamentario de Juan de Beurco. Potosí 


\section{Delio en el argénteo monte: Nuevos datos en torno a la vida de Diego Mexía}

que Diego Mexía de Fernangil, o "Delio" como le gustaba llamarse en términos literarios (Gil Fernández, 2008:70), vecino de la Villa Imperial de Potosí, redactó y finalizó la Segunda parte del Parnaso Antártico de divinos poemas.

\section{LA GUERRA ENTRE VICUÑAS Y VASCONGADOS}

Algo que Diego Mexía debió presenciar fueron las grandes alteraciones que tuvieron lugar en Potosí, entre 1622 y 1625, entre las distintas naciones que residían en la villa, conocidas en la historiografía boliviana como la "guerra entre vicuñas y vascongados". Estas luchas, además de ocasionar una gran cantidad de muertos y heridos, afectaron de manera sensible el aparato productivo de la villa: las labores mineras decrecieron, varios ingenios paralizaron operaciones, algunos fueron destruidos, los contingentes de la mita se redujeron. De la misma manera el tráfico mercantil se resintió, varios mercaderes perdieron sus capitales, a otros les fueron saqueadas sus tiendas y, peor aún, el tránsito de mercaderías a Potosí fue afectado, puesto que en determinados momentos, los "vicuñas" tomaron el control de los caminos que conducían a la villa. ${ }^{13}$

Aún ahora no se sabe el grado de participación que el poeta tuvo en los disturbios, si es que en verdad lo tuvo; dado su origen sevillano, es posible inferir que hubiese sentido simpatía por los vicuñas, bando en el que se agrupaban andaluces, castellanos y extremeños. Sin embargo, al ser un comerciante ya establecido en la villa desde hacía varios años, es posible también que le hubiera tocado ser víctima de los atropellos que sufrieron distintos mercaderes durante la "guerra". Por otro lado, existe una ligera sospecha de que el esposo de su hija, Pedro Julián Mondragón, hubiese tenido simpatías por los vascos; seguro es, en todo caso, que Pedro Julián, como dueño de ingenio y de minas, precautelando obviamente sus intereses, se puso del lado de la autoridad real. De ello da fe su participación, el 7 de noviembre de 1623 , en una junta en la que las principales autoridades, mineros y azogueros de Potosí se comprometieron a apoyar a la justicia real para dar con los autores del atentado de 6 de septiembre, cuando un grupo de vicuñas asaltó la casa del corregidor

25 de noviembre de 1619. Ambos se obligaban de pagar 1.788 pesos; la suma era el valor de 25 quintales, 54 libras y 8 onzas de "azogue neto en caldo" que habían comprado de Zamudio.

${ }^{13}$ Los relatos de la época se refieren en términos de "guerra", a las luchas entre los distintos grupos regionales de la península ibérica (vascos, extremeños, castellanos, andaluces, portugueses, etc.), o "naciones" como son denominadas en las fuentes, que tuvieron lugar en Potosí en la década de 1620. El detonante de estas luchas fueron las pugnas por el poder local en la Villa. Se acusó al grupo vasco, que ya poseía un gran poder económico, pues en sus filas estaban los mineros y azogueros más importantes, de querer acaparar el poder político al manipular las elecciones de alcaldes. Frente a este poderoso grupo vasco surgió un conjunto heterogéneo en el que se agruparon castellanos, extremeños, andaluces y muchos criollos; a cuyos miembros se les daría el apelativo de "Vicuñas" por llevar sombreros tejidos con lana de vicuña. La lucha que empezó por el control del poder local derivaría pronto en una lucha de carácter social, cuyos alcances aún hoy no quedan del todo claros. La obra fundamental en torno a estos acontecimientos sigue siendo la de Alberto Crespo (1969). 


\section{Pablo Luis Quisbert Condori}

Felipe Manrique, matando a algunos de sus allegados y sirvientes e hiriendo al mismo corregidor (ALP/ACC C.1 Vol. $2 \mathrm{~N}^{\circ} 46$ ).

Ahora bien, otros cuatro escritores, a los cuales Mexía de Fernangil debió conocer, tuvieron una destacada participación en las luchas potosinas. Uno de ellos es el capitán Juan Sobrino, poeta criollo y uno de los líderes del bando de los vicuñas, de quien dice el cronista Arzáns que había escrito una historia de Potosí en octavas (1965. vol. 2:122). El otro es don Gabriel Gómez de Sanabria, fiscal de la Audiencia de Charcas, quien escribió una relación de los sucesos de Potosí, pero que también era poeta y había traducido a Marcial, siendo celebrado por el mismo Lope de Vega (Barnadas 2002, vol. 1:946-947).

El tercero es Juan de Cabrera Girón quien, además de ser un destacado arbitrista, se sabe que gustaba de las letras y escribió una comedia titulada El azahar de Mojotoro (Ramírez del Águila, 1978:32). Asimismo, Cabrera Girón, propietario de haciendas, dueño de minas en el Cerro Rico y de ingenios en la Ribera de Potosí, será acusado de ser uno de los principales instigadores y movedores de los vicuñas.

La identidad del cuarto escritor aún es un misterio. Se trata del anónimo autor del Tratado de una disputa entre dos amigos, el uno castellano de Burgos y el otro vascongado, en la Villa de Potosí, reino del Perú..$^{14}$ En este tratado - fechado en 1 de julio de 1624- dos amigos, uno vasco y el otro castellano, entablan un diálogo en el cual cada uno alaba el papel que le cupo a su nación en la construcción de la historia y la grandeza de España, intentando, al mismo tiempo, echar en cara a su interlocutor las infidelidades o las tachas de su nación.

\section{El MATRIMONIO DE DOÑA CATALINA MEXÍA DE CABRERA}

Si bien poco se sabe de la posición que tomó Mexía de Fernangil durante las luchas, sí se tiene constancia de que durante la "guerra" casó a una de sus hijas. Es en diciembre de 1624 cuando tuvo lugar el matrimonio de doña Catalina Mexía de Cabrera con Diego de Mayuelo, quien con el tiempo se convertiría en miembro del cabildo de la villa.

Ya se ha dicho que la familia Mayuelo estaba muy vinculada con la familia de Mexía de Fernangil, desde al menos 1615. Sin embargo, esta boda fue precedida por una escena digna de la literatura del Siglo de Oro. Por lo visto, al momento de producirse el compromiso de matrimonio, Mexía de Fernangil se hallaba en una precaria situación económica, había invertido la mayor parte de sus capitales en un

\footnotetext{
${ }^{14}$ El manuscrito original se encuentra en la Biblioteca Nacional de España (BNE/Mss. 11045). Existe una versión impresa del siglo XIX, la que sin embargo parece haber sido hecha con base en otro manuscrito.
} 


\section{Delio en el argénteo monte: Nuevos datos en torno a la vida de Diego Mexía}

préstamo que hizo a su yerno Pedro Julián Mondragón ${ }^{15}$ y, al mismo tiempo, sus negocios mercantiles no iban bien. Esto último era comprensible puesto que, para entonces, las luchas civiles entre naciones en la Villa Imperial de Potosí atravesaban sus etapas finales, pero la actividad mercantil aún no se había repuesto del todo.

Todo ello llevó a que el mercader-poeta tenga problemas para cumplir con la dote de la novia. Los detalles acerca de cómo resolvió los mismos, sólo los contaría en su lecho de muerte, casi diez años después

...declaro que al tiempo y cuando el dicho veinte y cuatro Diego de Mayuelo casó con la dicha doña Catalina Mexía de Cabrera, mi hija, otorgó escritura de dote en su favor, en la cual se da fe de cómo el susodicho recibió de mí, por bienes, dote y caudal conocido de la susodicha diez mil pesos corrientes de a ocho reales, los seis mil pesos dellos en seis barras de plata, que confesó valer la dicha cantidad y los cuatro mil pesos restantes en un poder y cesión en causa propia que le di, para que cobrase de Pedro Julián Mondragón, difunto, que me debía por una escritura de obligación que en mi favor otorgó de mayor cuantía... y aunque en la dicha escritura de recibo de dote que el susodicho otorgó a favor de la dicha mi hija se dio fe por el presente escribano del recibo de los dichos seis mil pesos en seis barras de plata, la verdad es que el entrego dellas fue supuesto, y que no se las entregué ni el dicho veinte y cuatro las recibió, mas de tan solamente el traslado de la escritura contra el dicho Pedro Julián Mondragón, y el haber hecho y otorgado el dicho veinte y cuatro la dicha escritura de dote supuesta en la forma dicha fue a ruego y persuasión mía, por estar pobre y no tener plata que darle, y no se entendiese ni supiese que no le daba con la dicha mi hija más dote que los cuatro mil pesos en la dicha cesión contenidos, porque luego que se otorgó la dicha carta de dote, me volví a llevar los dichos seis mil pesos en las dichas seis barras, para con ellas satisfacer como satisfice a la persona que me las dio para el dicho efecto. ${ }^{16}$

Para Mexía de Fernangil, al igual que para muchos de sus contemporáneos, la honra lo era todo; lo cual explica que tuviera que recurrir a la estratagema de prestarse las seis barras de plata y escenificar la entrega de la dote.

\section{EL DESASTRE DE LA LAGUNA DE CARICARI}

En la epístola a don Diego de Portugal, presente en la segunda parte del Parnaso Antártico, Diego Mexía relata una serie de eventos nada venturosos de la historia del Perú: terremotos, erupciones volcánicas, pestes, incursiones de piratas, etc. Su intención es presentar estos desastres como avisos divinos, una suerte de

\footnotetext{
${ }^{15}$ A través del testamento del poeta, puede saberse que Diego Mexía prestó en cierta oportunidad a Pedro Julián Mondragón, 16.000 pesos corrientes, una cifra bastante considerable; y que en otra ocasión pagó, como fiador, una deuda que había adquirido Mondragón (AHP/EN 86 f. 2922v).

${ }^{16}$ AHP/EN 86 fs. 2917r-2924v. Testamento de Diego Mexía de Fernangil, hecho por poder por Francisco Mexía. Potosí 8 de mayo de 1634. La cita es de los fs. f.2918v-2919r.
} 


\section{Pablo Luis Quisbert Condori}

anuncios de un gran castigo que sobrevendría al Perú a raíz de los pecados de España y los españoles, entre ellos los abusos cometidos contra los indios.

Este terrible castigo llegó para los habitantes de la Villa Imperial de Potosí, al menos así lo creerían ellos, el 15 de marzo de 1626. Ese día el dique de la laguna de Caricari cedió ante la fuerza de las aguas acumuladas, dando lugar a una inundación que arrasó con los ingenios y las viviendas que se encontraban en la Ribera de Potosí y sus cercanías, causando asimismo decenas de muertos.

Al tener sus casas y sus negocios muy cerca de la plaza principal de la villa, Mexía de Fernangil parece no haber sido golpeado directamente por la catástrofe. Sin embargo, su yerno, Pedro Julián Mondragón, sería uno de los principales afectados por la inundación, pues el ingenio que poseía en la Ribera resultó muy dañado, aunque el cronista Vásquez de Espinosa dice que fue uno de los que quedaron en condiciones para volver a procesar los metales (1958:590). En todo caso, los ingenios que como el de Mondragón no habían sido destruidos por completo, tardaron cerca de un año en volver a la normalidad.

Sin embargo, una desgracia mayor sobrevendría a la familia de Diego Mexía, pues en algún momento, a fines de la década de 1620, su hija Francisca de Miranda y su yerno Pedro Julián Mondragón fallecerían. No hay datos por ahora que aclaren si estas muertes tuvieron lugar al mismo tiempo o con un intervalo entre una y otra; menos aún la manera como se produjeron: si se debió a un accidente, alguna enfermedad, ${ }^{17} \mathrm{o}$ si los esposos perecieron durante la inundación. ${ }^{18}$

\section{DIEGo MEXÍA DE FERNANGIL Y EL TRIBUNAL DE LA INQUISICIÓN}

Sabido es que Mexía de Fernangil estuvo vinculado con el Tribunal de la Inquisición; de hecho en la segunda parte del Parnaso Antártico se presenta a sí mismo como "ministro del Santo Oficio de la Inquisición en la visita y corrección de los libros". En Potosí, Mexía alternó los negocios mercantiles y su actividad de escritor con la revisión y censura de libros. Lewis Hanke ha mostrado que revisó, en 1622, un ejemplar de la primera edición de Os Lusiadas de Luís de Camoens (1965, vol. 1:lxvii). Por su parte, Pedro Guibovich menciona otras dos piezas que habría revisado: la primera en julio de 1617, una de San Atanasio titulada Athanasii Magni Alexandrini Episcopi graviss. scriptoris et sanctiss martyris, opera in quatuor

\footnotetext{
${ }^{17}$ Como las terribles epidemias de tabardillo y de viruela que asolaron la Villa Imperial de Potosí en 1628.

${ }^{18}$ La muerte de su hija y su yerno llevó a que Mexía de Fernangil se hiciera cargo de la tutela de su nieto Gerónimo de Mondragón, quien habría nacido alrededor de 1624; así como de la administración de los bienes, minas, ingenio e intereses de Pedro Julián Mondragón; unos intereses que, ya se ha visto, habían quedado sumamente afectados por la inundación de 1626. La administración de la herencia de Mondragón debió consumir una buena parte del tiempo y energías del poeta, puesto que en su testamento se hace mención a que tuvo que hacer frente a un pleito de los acreedores de Pedro Julián Mondragón.
} 


\section{Delio en el argénteo monte: Nuevos datos en torno a la vida de Diego Mexía}

tomos distributa, obra que pertenecía a la biblioteca del colegio jesuita de Potosí; y la segunda en febrero de 1621, un volumen titulado Annotationes et lucubraciones in Canticum Canticorum (2003:165).

Pero al margen de ser censor y corrector de libros por la Inquisición, ${ }^{19}$ gracias a su testamento e inventario, puede saberse que fue, asimismo, familiar del Santo Oficio, cargo muy honroso y para cuya obtención hubo de realizar una prueba de limpieza de sangre. Al parecer, Mexía de Fernangil estaba orgulloso de ser parte del Santo Oficio: ser familiar, aspiración de muchos en la época, le otorgaba ciertos privilegios, entre ellos, el de ser procesado solamente por la Inquisición; el aprecio que tenía a su familiatura quedará consignado en el inventario de sus bienes, gracias al cual se puede saber que el poeta tenía la encomienda de oro, es decir, la insignia de familiar del Santo Oficio, primorosamente guardada en un "cofrecillo de plata". ${ }^{20}$

\section{CÓFRADE DE LA SANTA VERACRUZ}

En el poder que dio para testar, Mexía de Fernangil pidió expresamente ser enterrado en el convento de San Francisco de la Villa Imperial de Potosí, “....en la bóveda de la capilla de la Veracruz de donde soy veinte y cuatro". ${ }^{21}$ La pertenencia del poeta a esta cofradía, es muy reveladora. A fines del periodo medieval, la creciente obsesión por la pureza de sangre y la asociación entre nobleza y limpieza de sangre llevó a la conformación de cofradías "de la Sangre" y de la "Vera Cruz" alentadas por las órdenes de San Francisco y Santo Domingo (Rucquoi, 2000:357). En estas cofradías se congregaban las personas que presumían ser descendientes de cristianos viejos y, al margen de sus actividades piadosas, la cofradía les permitía establecer marcadas diferencias con el resto de la población, a la par de reforzar su identidad como grupo. La distinción será pues uno de los rasgos más sobresalientes de la cofradía potosina de la Santa Vera Cruz, y es por ello que desde el principio será sólo una cofradía de españoles, pero de los más nobles, ricos y poderosos; lo cual la convertirá en una de las más prestigiosas de la Villa. ${ }^{22}$

\footnotetext{
${ }^{19}$ Recientemente, junto con Marcela Inch, hemos logrado ubicar otros cuatro libros revisados por Diego Mexía de Fernangil.

${ }^{20}$ AHP/EN 86 f.2655v. Probablemente vinculadas también al ejercicio de su familiatura, hayan estado las "prisiones de fierro" que se hallaron en su inventario; pues como es sabido, los familiares del Santo Oficio estaban obligados a prestar ayuda a los Comisarios en las distintas diligencias que debían realizar; entre ellas la de prender a los acusados de delitos de fe.

${ }^{21}$ Mayores datos sobre la cofradía del Santo Cristo de la Vera Cruz o la Santa Vera Cruz de Potosí, en Quisbert (2008:271-414).

${ }^{22}$ La Santa Vera Cruz era pues el espacio ideal para alguien como Diego Mexía de Fernangil, orgulloso de sus orígenes y que buscó un cargo tan honroso como el de familiar del Santo Oficio. El ser miembro de esta cofradía, y más aún el haber desempeñado el cargo de veinticuatro de la misma, debió acrecentar aún más el prestigio del poeta, a la vez que le permitió relacionarse con la élite de la Villa Imperial.
} 


\section{Pablo Luis Quisbert Condori}

\section{LA RELACIÓN CON LOS LEÓN PINELO}

La Villa Imperial de Potosí con su famoso cerro no sólo fue el motor económico del virreinato del Perú, sino que, también, un centro generador e irradiador de cultura. Larga es la lista de escritores, poetas, artistas y místicos que se dieron cita en Potosí durante los años que Mexía de Fernangil vivió en ella, y que le dieron a la Villa Imperial un aire de ciudad (además de opulenta) culta, letrada y devota. Con todo, lo que en esta ocasión queremos confirmar, es la estrecha relación que existió entre la familia de Diego Mexía de Fernangil y la de Diego López de León, este último padre de los afamados Antonio de León Pinelo, Juan Rodríguez de León y Diego de León Pinelo. Esta relación queda patente a través del testamento de Diego López de León, de 1644, en el que declara

Yten declaro que yo presté a doña Magdalena Mexía para el entierro de su madre cuatrocientos y cuarenta y siete pesos de a ocho reales y que el doctor don Diego Mexía de Cabrera su hermano canónigo de Chuquisaca me escribió tomaba a su cargo esta deuda para pagármela. (Porras Barrenechea, 1945:619).

Magdalena Mexía, a la que hace referencia López de León, era una de las hijas de Diego; asimismo el doctor Diego Mexía de Cabrera era el hijo mayor del poeta. Es probable que la relación entre ambas familias se hubiera dado ya en la década de 1610, pues tanto Diego Mexía de Fernangil como Diego López de León, a quien también se conocía como Diego López de Lisboa, eran mercaderes; pero es más seguro que esta relación se desarrollara, sobre todo, en Potosí, donde López de León se estableció con sus hijos menores, Diego y Catalina, hacia 1622, luego del fallecimiento de su esposa; y a donde arribaría asimismo su hijo, Juan Rodríguez de León, quien serviría el curato de la iglesia mayor de Potosí entre 1623 y principios de 1627, donde se destacaría asimismo como un gran predicador.

Ahora bien, algo de especial hubo de existir en la relación entre Diego Mexía de Fernangil, familiar del Santo Oficio, y Diego López de León, cuyos padres habían sido procesados por la Inquisición en Portugal y quemados en la hoguera por judaizantes. Las distintas facetas en esta relación aún quedan por investigarse, ${ }^{23}$ pero en principio hay algo en común y es la gran cultura libresca de ambas familias; pues tanto los padres, Diego Mexía de Fernangil y Diego López de León, como los hijos Diego Mexía de Cabrera, Antonio de León Pinelo, Juan Rodríguez de León y Diego de León Pinelo, a más de ser asiduos lectores, serían destacados escritores.

\section{LOS MOMENTOS FINALES}

Al iniciarse la década de 1630, Mexía de Fernangil ya era un hombre entrado en años. A principios de 1634, sus condiciones de salud eran tan precarias, que no

\footnotetext{
${ }^{23}$ Gil Fernández sugiere un probable origen converso para Diego Mexía de Fernangil. Sin embargo, los indicios que presenta, aunque resultan interesantes, no son del todo convincentes (2008:88-96).
} 


\section{Delio en el argénteo monte: Nuevos datos en torno a la vida de Diego Mexía}

pudiendo dictar en persona su testamento, el 14 de enero otorgó un poder a su esposa María de Miranda, a su hermano Francisco Mexía y a su yerno Diego Mayuelo para que lo hicieran. Sin embargo, el poder fue lo suficientemente extenso como para que el poeta dejara establecido su origen y vecindad, quiénes fueron sus padres, el nombre de su esposa e hijos, la historia de la dote de doña Catalina Mexía de Cabrera, el deseo que tenía de ser enterrado en San Francisco y el criterio que debía seguirse para repartir la herencia que dejaba a sus hijos.

Finalmente, este gran poeta de Potosí, dejó de existir en algún momento entre el 14 de enero, cuando otorgó el poder, y el 18 de enero de 1634, día en que un escribano dio fe de su muerte

Yo Baltasar de Barrionuevo escribano del rey nuestro señor, público del número de la Villa Imperial de Potosí, doy fe y testimonio de verdad que hoy día de la fecha desta, vide muerto naturalmente a lo que pareció a Diego Mexía de Fernangil, a quien en su vida conocí. El cual estaba en un aposento de las casas de su morada, en un ataúd amortajado y revestido con el hábito de la orden de San Francisco y para que dello conste, de pedimento de los albaceas del dicho difunto, doy el presente en la dicha Villa de Potosí a diez y ocho días del mes de enero de mil y seiscientos treinta y cuatro años (AHP/EN 86 f. 2921r).

\section{LAS HONRAS FÚNEBRES}

En el cuarto de siglo que vivió en Potosí, Mexía de Fernangil se había convertido en un vecino respetado y reconocido en la Villa Imperial, de ahí que su entierro parece haber convocado a los notables y a buena parte de la población potosina; a fin de cuentas, se trataba de uno de los habitantes más ilustres que había tenido la villa. Como fue su deseo, el cuerpo de Diego Mexía sería revestido con el hábito franciscano y enterrado en la capilla de la Santa Vera Cruz en el convento de San Francisco. Asimismo, al haber sido veinticuatro de la cofradía de la Vera Cruz, se da por descontado que los miembros de la misma debieron asistir a su entierro con sus estandartes y toda la parafernalia que se acostumbraba en estas ocasiones.

De hecho, el entierro y las honras fúnebres parecen haberse hecho con mucha solemnidad y hasta con cierta pompa; pues cuando en marzo de 1634, su viuda doña María de Miranda hizo las cartas de pago de lo que se había gastado, la suma llegó a los 1.220 pesos corrientes, una cifra bastante considerable para la época (AHP/EN 86 fs. 2658r-f.2661v). Del conjunto de estos gastos, llama la atención la gran cantidad de dinero que se gastó en cera ( 372 pesos), lo que habla del ambiente solemne que rodeó a las honras. De la misma forma, son llamativos los 50 pesos que se pagaron por asentar al poeta como veinticuatro de la Cofradía de Santa Ana. Es muy probable que Mexía de Fernangil fuese ya cófrade y que uno de sus últimos deseos fuera ser asentado como veinticuatro de la cofradía de esta santa, a la que dedicó su Oración en alabanza de la señora Santa Ana. En síntesis, el de Diego Mexía de Fernangil, fue un entierro costoso, acorde al prestigio y reconocimiento que el poeta sevillano gozaba en Potosí. 


\section{Pablo Luis Quisbert Condori}

\section{EL INVENTARIO DE SUS BIENES Y EL TESTAMENTO}

Entre la muerte de Diego Mexía de Fernangil y la realización del inventario de bienes, pasaría todavía algún tiempo. Finalmente, el inventario se haría el 23 de marzo de 1634, y a través de él puede tenerse una idea acerca de la vida cotidiana del poeta y de los bienes que atesoraba. ${ }^{24}$ Así, algo que resalta a primera vista es que, si bien como mercader Mexía de Fernangil atravesó en algunos momentos vicisitudes económicas, en última instancia pertenecía a uno de los sectores relativamente acomodados y notables de la sociedad potosina. De hecho, al momento de hacerse el inventario, se encontraron tres mil pesos en reales, lo cual era una pequeña fortuna para los parámetros de la época. Asimismo, y tal como era costumbre en la Villa, la vajilla que usaba era casi toda de plata. Sin embargo, el poeta parece no haber hecho gala de mucha ostentación, pues solamente poseía dos esclavas: “...la una llamada Inés, criolla de edad de veinte y seis años poco más o menos, y la otra María Angola de edad de treinta años”.

El rechazo a la ostentación y al lujo se nota más claramente en su vestimenta; pues - a excepción de un "jubón de terciopelo azul" - los jubones, calzones y capas de Mexía de Fernangil eran casi todos de color negro o pardo, siguiendo en esto la sobriedad en el vestir, característica del reinado de Felipe II y que el poeta parece haber mantenido hasta sus últimos años.

Donde sí puso cierto esmero fue en las pinturas y objetos de devoción; pues junto a unos lienzos de San Francisco y de la Concepción, advocaciones de clara influencia franciscana, Mexía de Fernangil poseía, también, un lienzo de San José, otro de la Virgen, un niño Jesús de bulto, "una tabla de Nuestra Señora con su velo carmesí" y "veinte y dos retablos de diferentes pinturas y retratos"; aunque es de lamentar que no exista el detalle de estos últimos. Asimismo, el poeta se sintió siempre muy vinculado a su ciudad natal; lo demuestra el lienzo que poseía donde estaba "...retratada la ciudad de Sevilla" y la devoción que tenía a Santa Justa y Santa Rufina, pues tenía un lienzo al óleo de estas santas, a las cuales menciona también en su Oración en alabanza de la señora Santa Ana, incluida dentro de la Segunda Parte del Parnaso Antártico (f. 150r).

Pero además de ser un cristiano devoto, Diego Mexía de Fernangil era también un hombre de armas; de ahí que poseyera asimismo una espada, una daga plateada, una alabarda y una escopeta.

En cuanto a los libros presentes en el inventario de bienes de Mexía de Fernangil, dado el tenor del mismo inventario, nos inclinamos a creer que se trata de su biblioteca personal más que de mercadería para vender. De tratarse de su biblioteca, puede considerarse de tamaño mediano pues el inventario

${ }^{24}$ AHP/EN 86 fs. 2655r-2658r. Inventario de los bienes de Diego Mexía de Fernangil. Potosí 23 de marzo de 1634. 


\section{Delio en el argénteo monte: Nuevos datos en torno a la vida de Diego Mexía}

describe que estaba compuesta de "cincuenta y cuatro libros, chicos y grandes" y "veinte y siete libros en tabla, grandes y pequeños". No hay mayor detalle acerca de los autores y el título de las obras, con la excepción de "las obras de Lipcio en siete tomos y uno más pequeño" que fueron descritas aparte. Es decir, se trata de una biblioteca inferior al centenar de obras; sin embargo, es obvio que Mexía de Fernangil leyó más libros de los que poseía, lo que nos remite a las observaciones que hace Marcela Inch acerca de la circulación de libros en las ciudades de La Plata y Potosí en el siglo XVII (2008:417-537).

Mexía de Fernangil había sido un viajero incansable, sobre todo, en el camino que unía Potosí con Lima, la capital del virreinato ¿Cuántas veces el poeta hubo de recorrer esa ruta, pernoctando en los distintos tambos y ventas que jalonaban el camino: Yocalla, Vilcapujio, Challapata, Peñas, Oruro, Caracollo, Sicasica, Calamarca, Chuquiago, etc? Conforme su edad avanzaba, fue haciendo menos viajes. Como recuerdo de estos años de viajero, en el inventario quedarían registrados objetos ya viejos, como un almofrez, un quitasol y "unas alforjas, dos frascos, una bota chica y dos frezadas viejas". ${ }^{25}$ Finalmente, el inventario habla de la vivienda que habitó en la Villa Imperial de Potosí durante muchos años

Unas casas de [vi]vienda y morada questan en esta villa, en la calle arriba de la, Moneda, lindan por una parte con casas en que al presente vive Lorenzo de Garate, en que vivió y murió el dicho Diego Mexía. ${ }^{26}$

En cuanto al testamento, éste se hizo recién el 8 de mayo de 1634. Lo más probable es que la esposa del poeta, doña María de Miranda, su hermano Francisco Mexía y su yerno Diego de Mayuelo hubieran decidido poner en orden los bienes y cuentas de Diego Mexía antes de realizarlo. ${ }^{27}$

${ }^{25}$ El inventario consigna, asimismo, cosas que hacían a su oficio de mercader como una romana, "cuatro libros de cuenta de caja y un manual" y "dos candados grandes de mercader".

${ }^{26} \mathrm{AHP} / \mathrm{EN} 86$ f. 2657v. El testamento da una ubicación más precisa de estas casas: “....unas casas de vivienda y morada que están en la calle arriba de la Casa de la Moneda desta dicha villa, que lindan con casas del Colegio de la Compañía de Jesús y están en frente de las casas del veinte y cuatro Juan de Lázaro" (AHP/EN 86 f. 2923r). Por cierto que ambos textos se están refiriendo a la primera Casa de la Moneda que hubo en Potosí.

${ }^{27}$ Gracias a este testamento puede saberse que Mexía de Fernangil se hizo cargo de la administración de los bienes de Pedro Julián de Mondragón y del cuidado de su nieto Gerónimo de Mondragón. A priori, parece que Mexía de Fernangil administró bastante bien los bienes de Pedro Julián de Mondragón, encarando el pleito de acreedores y satisfaciendo las deudas de su yerno, incluyendo las grandes sumas que a él mismo le debía Mondragón (Mexía le había prestado 16.000 pesos y en otra ocasión había cancelado por él otra suma). Tal vez, sintiéndose ya enfermo, decidió traspasar la administración de los bienes y la tutela de su nieto a su hermano Francisco de Mexía, admitiendo (eso sí) que quedaba debiendo a Gerónimo de Mondragón 750 pesos. Por cierto, Mexía de Fernangil, parece haber sido bastante cuidadoso en los temas financieros, lo cual es lógico tratándose de un mercader, pues a excepción de la deuda que admitió tener con su nieto, el testamento aclara que no debía dinero a nadie más. 


\section{Pablo Luis Quisbert Condori}

LA FAMILIA

Desde ya, la documentación potosina aporta valiosos datos en torno a la ascendencia y la descendencia de Diego Mexía de Fernangil. Así en el poder para testar que el poeta-mercader suscribió el 14 de enero de 1634, dirá de sí mismo y de sus padres lo siguiente

En el nombre de Dios amen, sepan cuantos esta escritura vieren como yo Diego Mexía de Fernangil, familiar del Santo Oficio de la Inquisición, vecino desta Villa Imperial de Potosí del Pirú, y natural que soy de la ciudad de Sevilla reinos de España, hijo legítimo de Diego Mexía de Fernangil y de doña Juana de Cabrera su mujer, mis padres difuntos que santa gloria ayan, vecinos que fueron de la dicha ciudad (AHP/EN 86 f. 2917r).

El poeta alega ser pues hijo de Diego Mexía de Fernangil y de doña Juana de Cabrera, vecinos de Sevilla. De ahí que, salvo nueva evidencia, el Diego Mexía, “...hijo de Diego Mexía y de Leonarda de Torres”, que en 1582 “....se despachó a la provincia de Tierra Firme por mercader", y que Trinidad Barrera (2009:17) y Juan Gil (2008:68) creen que es el poeta sevillano, sería mas bien un homónimo.

Se confirma el dato proporcionado por Lohmman Villena, en el sentido de que la esposa del poeta llevó el nombre de María de Miranda; sin embargo, doña María de Miranda parece no haber sido analfabeta como se suponía, pues su firma aparece en varias actuaciones notariales. Con todo, la gran novedad aportada por la documentación potosina, es la identidad de los cinco hijos, dos varones y tres mujeres, que tuvieron Diego Mexía y doña María de Miranda.

En cuanto a sus tres hijas, se ha dicho líneas atrás que Francisca de Miranda casó con Pedro Julián Mondragón y ambos fallecieron en Potosí, probablemente a fines de la década de 1620. De doña Catalina Mexía de Cabrera se ha mencionado asimismo que en diciembre de 1624 contrajo matrimonio con Diego de Mayuelo. La tercera de las hijas, doña Magdalena Mexía, cumpliría con la voluntad de su padre y se quedaría acompañando a su madre hasta su fallecimiento, tal cual lo atestigua el testamento de Diego López de León. ${ }^{28}$

En cuanto a los hijos varones, poco se conoce hasta ahora de Pedro Mexía -el menor de ellos - salvo que vivió en Potosí, al menos hasta 1634, fecha de la muerte de su padre. El miembro más esclarecido de los descendientes de Diego Mexía de Fernangil sería su hijo mayor, el licenciado Diego Mexía de Cabrera quien, nacido en Lima, había estudiado en la facultad de cánones en la Universidad de San Marcos. Mexía de Cabrera ejerció de abogado en la Audiencia de Lima y en determinado momento decidió seguir la carrera eclesiástica, llegando a ser cura en la Villa Imperial

\footnotetext{
${ }^{28}$ No queda muy en claro todavía dónde se produjo el fallecimiento de doña María de Miranda; lo más probable es que hubiese tenido lugar en Potosí, pero no debe descartarse que hubiese regresado a Lima, luego de la muerte de Diego Mexía de Fernangil.
} 


\section{Delio en el argénteo monte: Nuevos datos en torno a la vida de Diego Mexía}

de Potosí. Aparentemente, en el año $1633,{ }^{29}$ emprendió viaje a España para obtener un cargo eclesiástico de mayor jerarquía. Nombrado racionero en la catedral de La Plata, retornará a Charcas en $1635 .{ }^{30}$ Diego Mexía de Cabrera, heredero de la cultura libresca de su padre, destacará asimismo como un gran canonista y fruto de sus trabajos, se publicará en 1655 su obra Práctica y estilo judicial en defensa de la inmunidad del fuero eclesiástico. ${ }^{31}$

\section{PALABRAS FINALES}

Mediante lo expuesto se puede tener una idea más precisa acerca de los años que Diego Mexía de Fernangil pasó en la Villa Imperial de Potosí; una ciudad en la que decidió establecerse, donde adquirió vecindad, en la que realizó una buena parte de su obra que permanece inédita y otra aún perdida, y donde finalmente acabó sus días. Sin embargo, la documentación conservada en los archivos bolivianos - una pequeña parte de la cual ha sido presentada en este trabajopuede deparar aun más sorpresas y novedades literarias, no sólo en torno a la vida y la obra del poeta sevillano, sino también de los círculos intelectuales existentes en Charcas en el siglo XVII.

\section{Coordinadora de Historia-La Paz - Investigadores asociados* Calle Moxos 250-tembladerani Casilla 4291, La Paz (Bolivia) pquisbert@gmail.com}

\section{BIBLIOGRAFÍA}

Arzáns De Orsúa y Vela, Bartolomé. Historia de la Villa Imperial de Potosí. Riquezas incomparables de su famoso cerro, grandezas de su magnánima población. Sus guerras civiles y casos memorables. (Ed.). Lewis Hanke y Gunnar Mendoza. Providence-Rhode Island: Brown University Press, 1965.

Barnadas, Josep. Bibliotheca Boliviana Antiqua. Impresos coloniales (1534-1825). 2 vols. Sucre: ABNB / Centro de Estudios Bolivianos Avanzados, 2008.

Diccionario Histórico de Bolivia. Sucre: Grupo de Estudios Históricos, 2002.

Barrera López, Trinidad. "De Academias, transterrados y Parnasos Antárticos", en América sin nombre. $\mathrm{N}^{\circ} 13-14$. (2009):15-21.

\footnotetext{
${ }^{29}$ La fecha la da Antonio de Herrera, que por cierto es el único que otorga a Mexía de Cabrera también el apellido Fernangil: "El señor doctor don Diego Mejía de Cabrera y Fernangil fue a España el año de treinta y tres, después de haber sido cura y vicario de la Villa de Potosí y sido visitador general del arzobispado de Lima; trajo una ración a esta santa iglesia y vino por provisor del Ilustrísimo señor arzobispo don Francisco de Borja, de quien asimismo fue visitador; por sus buenas partes, Su Majestad le hizo merced este año de treinta y ocho de promoverle a esta canonjía" (1996:88-89).

${ }^{30}$ El expediente de información y licencia de pasajero a Indias de Mexía de Cabrera y de los dos criados que llevó se encuentra en AGI/Contratación 5416, Nº 36.

${ }^{31}$ Impresa en Madrid por Julián de Paredes. Un comentario sobre esta obra en Barnadas 2008, vol. 1:410-411.
} 


\section{Pablo Luis Quisbert Condori}

------- "La Primera Parte del Parnaso Antártico de Diego Mexía de Fernangil, Sevilla, 1608", en Andalucía y América en el siglo XVII. Actas de las III Jornadas de Andalucía y América. Vol. 2. Sevilla: Escuela de Estudios Hispano-Americanos EEHA. 1985:213-229.

Córdova, Diego De. Vida, virtudes y milagros del apóstol del Perú, el B. P. Fr. Francisco Solano de la seráfica orden de los menores de la regular observancia, patrón de la ciudad de Lima. Madrid: Imprenta Real, 1676.

Crespo, Alberto. La Guerra entre Vicuñas y Vascongados. La Paz: José Camarlinghi. Colección Popular, 1969.

Gil Fernández, Juan. "Diego Mexía de Fernangil: un perulero humanista en los confines del mundo", en El humanismo español entre el Viejo Mundo y el Nuevo. León: Universidad de Jaén / Universidad de León, 2008:67-142.

Guibovich, Pedro. Censura, libros e Inquisición en el Perú colonial, 1570-1754. Sevilla: Consejo Superior de Investigaciones Científicas, 2003.

Hanke, Lewis; Mendoza, Gunnar. "Bartolomé Arzáns de Orsúa y Vela: su vida y su obra", en Bartolomé Arzáns de Orsúa y Vela. Historia de la Villa Imperial de Potosí. Riquezas incomparables de su famoso cerro, grandezas de su magnánima población. Sus guerras civiles y casos memorables. Vol. 1. Providence-Rhode Island: Brown University Press, 1965:XXVII-CLXXXII.

Herrera y Toledo, Antonio de. Relación Eclesiástica de la Santa Iglesia Metropolitana de los Charcas (1639). Edición de Josep Barnadas. Sucre: Archivo y Biblioteca Arquidiocesanos Monseñor de los Santos Taborga, 1996.

Inch, Marcela. "Libros, comerciantes y libreros: La Plata y Potosí en el Siglo de Oro", en La construcción de lo urbano en Potosí y La Plata. Siglos XVI y XVII. Sucre: Ministerio de Cultura de España / ABNB, 2008:417-537.

Lohmann Villena, Guillermo. "Huellas renacentistas en la literatura peruana del siglo XVI”, en La tradición clásica en el Perú virreinal. Lima: Sociedad Peruana de Estudios Clásicos / Universidad Nacional Mayor de San Marcos, 1999:115-127.

Pociña, Andrés. "El sevillano Diego Mexía de Fernangil y el humanismo en Perú, a finales del siglo XVI", en Anuario de Estudios Americanos No 40. 1983:163-184.

Porras Barrenechea, Raúl. "El testamento de Diego de León Pinelo", en Fénix $\mathrm{N}^{\circ} 3$. (1945):613-628.

Quisbert, Pablo. "Servir a Dios o vivir en el siglo: la vivencia de la religiosidad en la ciudad de La Plata y la Villa Imperial de Potosí", en La construcción de lo urbano en Potosí y La Plata. Siglos XVI y XVII. Sucre: Ministerio de Cultura de España / ABNB, 2008:271-414.

Ramírez Del Águila, Pedro. Noticias Politicas de Indias. Edición de Jaime Urioste. Sucre: Imprenta Universitaria, 1978.

Riva Agüero, José De La. "Diego Mexía de Fernangil y la Segunda Parte del Parnaso Antártico", en Actas y Memorias del Congreso de Historia y Geografia Hispanoamericana. Madrid: Jaime Batés, 1914:385-427.

Rucquoi, Adeline. Historia Medieval de la Península Ibérica. Michoacán: El Colegio de Michoacán, 2000.

Vásquez De Espinosa, Antonio. Compendio y descripción de las Indias Occidentales. Washington: The Smithsonian Institution. Smithsonian Miscellaneous Collections, 1958. 